\section{Multidisciplinary SCIENTIFIC JOURNAL OF MARITIME RESEARCH}

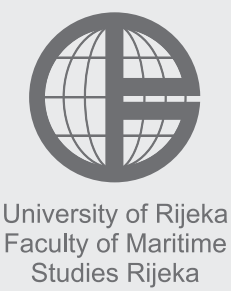

Multidisciplinarni

znanstveni časopis

POMORSTVO

\title{
Decision making background for the location of inland terminals
}

\author{
Tomislav Rožić ${ }^{1}$, Dario Ogrizović ${ }^{2}$, Marinela Galić ${ }^{1}$ \\ ${ }^{1}$ University of Zagreb, Faculty of Transport and Traffic Sciences, Vukelićeva 4, 10000 Zagreb, Croatia, e-mail: tomislav.rozic@fpz.hr \\ ${ }^{2}$ University of Rijeka, Faculty of Maritime Studies Rijeka, Studentska ulica 2, 51000 Rijeka, Croatia
}

\begin{abstract}
Inland terminals are becoming important objects (knots) in today's supply chain. This implies new methods to determine the location of inland terminal. Appropriate inland terminal location (ITL) decision depends on analyzing demand, employee's availability, investment capabilities and other factors. In this paper we present gravity center method and median method as quantitative ones and Analytic Hierarchical Process (AHP), ELECTRE and PROMETHEE as complex decision methods to determine inland terminal location. Given methods are implemented on the example of inland terminal location determination in Republic of Croatia.
\end{abstract}

\section{Introduction}

Inland terminals represent objects that enable port capacities disburdening and the expansion of the port gravitational areas. This makes them vital part in today's supply chain management. One of the most important trends in the inland terminal system are methods to determine location of inland terminals by satisfying different requirements.

Choosing the location of inland terminals has to be conducted with care, because it can cause irreversible consequences in urban planning and can create bottlenecks that lead to increase of the price of logistics services [1]. According to Sorensen et al. [2] the best approach to determine the location of inland terminal is the application of network models and the use of multi-criteria analysis.

In this paper we used the gravity center method and median method as quantitative ones and Analytic Hierarchical Process (AHP), ELECTRE and PROMETHEE as complex decision methods to determine inland terminal location. The analysis contains five cities across Croatia: Slavonski Brod, Karlovac, Koprivnica, Osijek and Split,

\section{ARTICLE INFO}

Original scientific paper Received 20 September 2016

Accepted 25 October 2016

\section{Key words:}

Inland terminals

AHP method

Gravity center method

Median method

ELECTRE method

PROMETHEE method which is referred to herein as the alternatives and five criteria which are evaluated.

In classical gravitation method the optimal inland terminal location (ITL) is determined as a point on the map where the total transport costs that are induced by transporting goods to and from $N$ different customers are minimal [11]. Because the costs depend on unit transport costs $R_{i}$, demand volume $V_{i}$ and the shortest distance $d_{i}$ from $i$ th customer to the optimal location as the center of gravity:

$$
\min T C=\sum_{i=1}^{N} V_{i} \cdot R_{i} \cdot d_{i}
$$

In median method the ITL is obtained by the calculation of the cumulative weight. Cartesian coordinates $\left(X_{i}, Y_{i}\right), i=1, \ldots, N$ are used for customers, and $\left(\bar{X}_{0}, \bar{Y}_{0}\right)$ are coordinates for ITL [6]. In the minimization of objective function, we use the Manhattan or taxi - cab metric pondered by weights $V_{i} \cdot R_{i}=w_{i}$

$$
\min T C=\sum_{i=1}^{N} w_{i} \cdot\left[\left|X_{i}-\bar{X}\right|+\left|Y_{i}-\bar{Y}\right|\right]
$$


Complex decision by AHP method is to rank criteria and alternatives in purpose to obtain optimal solution. Qualitative criteria are compared in pairs [8]. Preference is used in the process of finding optimal choice, in our case the location of inland terminal. It is usual to mark the weak preference relation by symbol $\preccurlyeq$. In our case $i \preccurlyeq j i \preccurlyeq$ $j$ represents that the location $j$ has weak preference over location $i$.

We calculate each coefficient $a_{i j}$ which represent the value preference of criterion $i$ ahead of criterion $j$ and construct matrix $A$ shown in (3). These coefficients present ranking preference from the same over weak, strong, demonstrated and absolute preference. In that case, $a_{j i}=1 / a_{i j}$ '

$$
A=\left[\begin{array}{cccc}
a_{11} & a_{12} & \ldots & a_{1 n} \\
a_{21} & a_{22} & \ldots & a_{2 n} \\
\vdots & \vdots & \ldots & \vdots \\
a_{n 1} & a_{n 2} & \ldots & a_{n n}
\end{array}\right]
$$

Criteria are obtained as the components of eigenvector $w$ and then can be ranked. In the procedure we also get maximal eigenvalue $\alpha_{\max }$ of the matrix $A$ using the power method.

In Elimination Et Choice Translating Reality (ELECTRE) method alternatives $a$ and $b$ are ranked by $a S b$ or $a P b$ if $a$ is at least good as $b$ or if $a$ is much better than $b$. Alternatives are ranked according the criteria, by counting criteria that support one of given alternative pair [4].

Preference Ranking Organization METHod for Enrichment Evaluation (PROMETHEE), for complex decision in a set of alternatives $S$, represent a problem [3]:

$$
\operatorname{Max}\left(f_{1}(a), \ldots, f_{k}(a)\right)
$$

where criterion functions $f_{i}(a)$ are defined discretely by sequences of arbitrary ordinal numbers assigned to each alternative. Preference function

$$
F: S \times S \rightarrow\{0,1\}
$$

is defined such that $F(a, b)=0$ means weak preference of $a$ over $b$ and $F(a, b)=1$ means strong preference of $a$ over $b$. If we assume that $F(a, b)=P(f(a)-f(b))=P(d)$, then $P(x)$ is some non-decreasing function which takes value zero for negative $d=f(a)-f(b)$. Problem could be defined vice versa, but the preference function must be defined first. In our paper we defined criterion functions first.

\section{Solution methods}

Given values in the classic gravitation problem (1) are $R_{i}, V_{i}$ and Cartesian coordinates for each customer in kilometer's units [11]. If we use the shortest, Euclidian, distance, then (1) is transforming into

$$
d_{i}=K_{i} \cdot \sqrt{\left(\bar{X}-X_{i}\right)^{2}+\left(\bar{Y}-Y_{i}\right)^{2}}
$$

where $K_{i}$ is strong unit weight value in coordinate system. Unknown ITL coordinates are obtained from necessary conditions for extrema:

$$
\frac{\partial T C}{\partial \bar{X}}=0 \text { and } \frac{\partial T C}{\partial \bar{Y}}=0
$$

After finding the derivative of the transport cost function $T C$, it is possible to express the unknown coordinates explicitly:

$$
\bar{X}=\frac{\sum_{i=1}^{N} \frac{V_{i} \cdot R_{i} \cdot X_{i}}{d_{i}}}{\sum_{i=1}^{N} \frac{V_{i} \cdot R_{i}}{d_{i}}} \quad \text { and } \quad \bar{Y}=\frac{\sum_{i=1}^{N} \frac{V_{i} \cdot R_{i} \cdot Y_{i}}{d_{i}}}{\sum_{i=1}^{N} \frac{V_{i} \cdot R_{i}}{d_{i}}}
$$

Initial average coordinates $\bar{X}_{0}, \bar{Y}_{0}$ are the mean values of $X_{i}, Y_{i}$ respectively, pondered by $V_{i} \cdot R_{i}$ according to the following formula:

$$
\bar{X}_{0}=\frac{\sum_{i=1}^{N} V_{i} \cdot R_{i} \cdot X_{i}}{\sum_{i=1}^{N} V_{i} \cdot R_{i}} \quad \text { and } \quad \bar{Y}_{0}=\frac{\sum_{i=1}^{N} V_{i} \cdot R_{i} \cdot Y_{i}}{\sum_{i=1}^{N} V_{i} \cdot R_{i}}
$$

The unknown values are found by iterative method through the following steps:

1. The initial $(\bar{X}, \bar{Y})$ is the arithmetic mean of given $\left(X_{i}\right.$, $\left.Y_{i}\right), i=1, \ldots, N$

2. With $(\bar{X}, \bar{Y})$, the distance $d_{i}$ can be calculated by (6)

3. Calculate the $T C$ by (1)

4. The new $(\bar{X}, \bar{Y})$ is now obtained by (8)

5. Calculate the $T C$ by (1) with new $(\bar{X}, \bar{Y})$

6. Repeat steps 2.-5. till the costs become the same under some tolerance

Problem described in (2) is solved using median method by finding a mean coordinate within $X_{i}$ and $Y_{i}$ separately, considering their weights [6]. After aligning the coordinates $X_{i}$ increasingly, we calculate the cumulative values for related sequence of weights. If $j$ - th cumulative value amounts a half or a more than a half of the last cumulative value, then $X_{j}=\bar{X}$. Formally, this method is written in following inequality conditions for $j$ - th coordinate:

$$
\sum_{i=1}^{j-1} w_{i}<\sum_{i=1}^{N} \frac{w_{i}}{2} \text { and } \sum_{i=1}^{j} w_{i} \geq \sum_{i=1}^{N} \frac{w_{i}}{2}
$$

Analogue solution method for $Y_{k}=\bar{Y}$ is written in following inequality conditions for $k$ - th coordinate:

$$
\sum_{i=1}^{k-1} w_{i}<\sum_{i=1}^{N} \frac{w_{i}}{2} \text { and } \sum_{i=1}^{k} w_{i} \geq \sum_{i=1}^{N} \frac{w_{i}}{2}
$$

Finally, optimal location is obtained as a pair $(\bar{X}, \bar{Y})=$ $\left(X_{j}, Y_{k}\right)$.

In AHP method, the maximal eigenvalue $\lambda_{\max }$ and its eigenvector $w$ for the matrix $A$ from (3) satisfies following relation [10]:

$$
A \cdot w=\lambda_{\max } \cdot w
$$

Each eigenvector's component is obtained, in the first iteration, by summing related row of matrix $A$. Vector in the first iteration is hardly close to the wanted eigenvector $w$. In the second iteration, elements in rows are summing for matrix $A \cdot A$. In the third iteration summing is done for $A \cdot A \cdot A$. Process stops when difference between compo- 
nents of two successive vectors are less then (small) value given in advance. The vector obtained in the last iteration is wanted eigenvector $w$ from (12).

Solving the complex decision problem by ELECTRE method presumes given matrix [13]

$$
H=\left[\begin{array}{cccc}
h_{11} & h_{12} & \ldots & h_{1 n} \\
h_{21} & h_{22} & \cdots & h_{2 n} \\
\vdots & \vdots & \ldots & \vdots \\
h_{m 1} & h_{m 2} & \ldots & h_{m n}
\end{array}\right]
$$

where elements $h_{i j}$ are numbers from an arbitrary ordinary scale such that every column describes order of given alternatives. So every $h_{i j}$ is a ranking estimation for $i$ - th alternative according to the $j$ - th criterion. Furthermore, the vector for ranking criteria is also necessary:

$$
B=\left[b_{1} b_{2} \ldots b_{n}\right]
$$

where components are elements of arbitrary ordinary scale. Considering $A$ and $B$ are given, one must proceed through the next steps.

1. Calculate the normalized decision matrix $R=\left(r_{i j}\right)$ with elements calculated by $a_{i j}$ from (12):

$$
r_{i j}=\frac{h_{i j}}{\sum_{i=1}^{n} h_{i j}{ }^{2}}
$$

2. Calculate the normalized weighted decision matrix $V_{i j}$ by values $b_{i}$ from (13):

$$
\begin{aligned}
& V=R \cdot\left[\begin{array}{cccc}
b_{1} & 0 & \cdots & 0 \\
0 & b_{2} & \cdots & 0 \\
\vdots & \vdots & \cdots & \vdots \\
0 & 0 & \cdots & b_{n}
\end{array}\right]= \\
& =\left[\begin{array}{cccc}
b_{1} r_{11} & b_{1} r_{12} & \cdots & b_{1} r_{1 n} \\
b_{2} r_{21} & b_{2} r_{22} & \cdots & b_{2} r_{2 n} \\
\vdots & \vdots & \ldots & \vdots \\
b_{m} r_{m 1} & b_{m} r_{m 2} & \ldots & b_{m} r_{m n}
\end{array}\right]
\end{aligned}
$$

3. Determinate concordance $\left(C_{k l}\right)$ and discordance $\left(D_{k l}\right)$ sets consisted of criteria indices $j$ by definition $C_{k l}=\left\{j, h_{k j} \geq h_{l j}\right\}$. Elements of nonconformity set consist of values $j$ that do not belong to the relevant conformity set.

4. Format concordance $(C)$ and discordance matrix $(D)$. $C$ matrix is $m \times m$ dimensional and it does not take value on diagonal. The elements of matrix $C$ are calculated by the following formula.

$$
c_{k l}=\sum_{j \in C_{k l}} b_{j}
$$

The elements of discordance matrix $(D)$ are calculated by the formula below:

$$
d_{k l}=\frac{\max _{j \in D_{k l}}\left|v_{k j}-v_{l j}\right|}{\max _{j \in J}\left|v_{k j}-v_{l j}\right|}
$$

5. Calculate domination in concordance matrix by the formula:

$$
\underline{c}=\sum_{k=1}^{n} \sum_{l=1}^{n} \frac{c_{k l}}{n(n-1)}
$$

6. Calculate domination in concordance matrix by the formula:

$$
\underline{d}=\sum_{k=1}^{n} \sum_{l=1}^{n} \frac{d_{k l}}{n(n-1)}
$$

7. Format Total Dominance Matrix $E=\left[e_{k l}\right]$ with elements obtained by multiplying related elements $f_{k l} \cdot g_{k l}$ from the obtained matrix $F=\left[f_{k l}\right]$ and matrix $G=\left[g_{k l}\right]$. Elements $f_{k l}$ are given by condition that if $c_{k l} \geq \underline{c}$ then $g_{k l}=$ 1 . Elements $g_{k l}$ are given by condition that if $d_{k l} \geq \underline{d}$ then $g_{k l}=1$. Otherwise, both elements equal zero.

8. The order of alternatives is defined by counting values 1 in related row for every alternative. Absolutely dominated alternative has the highest number of values 1 in its correspondence row.

PROMETHEE method given by (4) is based on assumption that decision maker defined criterion functions $f_{i}$ and its importance factors $\pi_{i}, i=1, \ldots, k$. For example, preference function can be defined by formula [3]:

$$
F(a, b)=P(f(a)-f(b))=P(d)= \begin{cases}0, & d \leq 0 \\ 1, & d>0\end{cases}
$$

Final result is obtained from the preference function values matrix with rows defined by every possible pair of alternatives, and columns defined by criteria. Every row as $k$-dimensional vector in dot product with $k$-dimensional vector of scalar weights gives decision intensities for each alternative pair.

Scalars obtained above are elements in matrix with alternatives in rows and in the columns. Elements in the $i$ - th row and $j$ - th column represents the flow from $i-$ th alternative to $j$ - th alternative. Then it is possible to calculate average input flow $T^{+}$and average output flow $T^{-}$for every alternative.

The bigger difference $T^{+}-T^{-}$is, the better alternative preference is.

\section{Solution methods applications}

In this chapter, the methods explained above are compared to each other. Every method takes the same alternatives given as the possible location for an ITL. There are Slavonski Brod, Karlovac, Koprivnica, Osijek and Split.

For solving the ITL problem by classical gravity method, according to (9), the initial ITL coordinates are obtained in the Table 1.

According to (8) further iterative performance is proceeded from initial point $\left(\bar{X}_{0}, \bar{Y}_{0}\right)=(140,173)$. In the Table 2 , the first step is shown. The next step is obtained by replacing the coordinates of previous step with the coordinates of the next step.

In this problem, the second step is immediately the final one as shown in Table 3. 
Table 1 Given values and initial ITL coordinates calculated

\begin{tabular}{|c|l|c|c|c|c|c|c|c|}
\hline No. & Alternative & Abscissa & Ordinate & Demand & Unit costs & Unit weight & Pondered & Coordinates \\
\hline & $a$ & $X_{i}$ & $Y_{i}$ & $V_{i}$ & $R_{i}$ & $V_{i} \cdot R_{i}$ & $X_{i} \cdot V_{i} \cdot R_{i}$ & $Y_{i} \cdot V_{i} \cdot R_{i}$ \\
\hline 1 & Slavonski Brod & 190 & 152 & 60 & 0.15 & 9.00 & 1710 & 1368 \\
\hline 2 & Karlovac & 43 & 190 & 72 & 0.15 & 10.80 & 464.4 & 2052 \\
\hline 3 & Koprivnica & 112 & 239 & 24 & 0.15 & 3.60 & 403.2 & 860.4 \\
\hline 4 & Osijek & 232 & 199 & 60 & 0.15 & 9.00 & 2088 & 1791 \\
\hline 5 & Split & 101 & 20 & 0.15 & 3.00 & 303 & 60 \\
\hline
\end{tabular}

Table 2 The step procedure from initial to the first step

\begin{tabular}{|c|c|c|c|c|c|c|c|c|}
\hline No. & $\boldsymbol{X}_{i}$ & $\boldsymbol{Y}_{i}$ & $\boldsymbol{V}_{i} \cdot \boldsymbol{R}_{i}$ & $\boldsymbol{X}_{i} \cdot \boldsymbol{V}_{i} \cdot \boldsymbol{R}_{i} / \boldsymbol{d}_{i}$ & $\boldsymbol{Y}_{i} \cdot \boldsymbol{V}_{i} \cdot \boldsymbol{R}_{i} / \boldsymbol{d}_{i}$ & $\boldsymbol{d}_{i}$ & $\boldsymbol{V}_{i} \cdot \boldsymbol{R}_{i} \cdot \boldsymbol{d}_{i}$ & $\boldsymbol{V}_{i} \cdot \boldsymbol{R}_{i} / \boldsymbol{d}_{i}$ \\
\hline & $\boldsymbol{k m}$ & $\boldsymbol{k m}$ & $\boldsymbol{k n}$ & $\boldsymbol{k n}$ & $\boldsymbol{k n}$ & $\boldsymbol{k} \boldsymbol{k}$ & $\boldsymbol{k} \boldsymbol{k}$ \\
\hline 1 & 190 & 152 & 9.00 & 47.48 & 37.98 & 54 & 324.15 & 0.25 \\
\hline 2 & 43 & 190 & 10.80 & 2.38 & 10.53 & 124 & 2103.89 & 0.06 \\
\hline 3 & 112 & 239 & 3.60 & 1.53 & 3.26 & 264 & 950.19 & 0.01 \\
\hline 4 & 232 & 199 & 9.00 & 6.83 & 5.86 & 306 & 2750.90 & 0.03 \\
\hline 5 & 101 & 20 & 3.00 & 2.94 & 0.58 & 103 & 308.88 & 0.03 \\
\hline
\end{tabular}

Table 3 The end of iteration process

\begin{tabular}{|c|c|c|c|}
\hline Iteration & $\overline{\boldsymbol{X}}$ & \multicolumn{2}{|c|}{ TC } \\
\hline 0 & 140 & 173 & 6599.70 \\
\hline 1 & 162 & 154 & 6438.01 \\
\hline 2 & 162 & 154 & 6438.01 \\
\hline
\end{tabular}

According to the Table 3, the best alternative for setting the ITL is Slavonski Brod because the distance between $(162,154)$ and $(190,152)$ is the smallest among all alternatives.

Median method requires increase ranking, separately done by $X$ and $Y$ coordinates of alternatives. After that, weights have to be assigned to related coordinates and then the conditions (10) and (11) are taken to get both median coordinate value. These median coordinates represent solution of ITL problem. Data is given in Table 4 .

Abscissa and ordinate of ITL solution by median method are bolded in Table 4, so $(\bar{X}, \bar{Y})=(190,190)$.

AHP method, according to (3) and (12) solves the problem by finding the eigenvector through the following procedure. Criteria definition and their relationships are given in Table 5.

Values from Table 5 are shown in the following matrix for the procedure.

Table 4 Weighted median coordinate value calculation

\begin{tabular}{|c|c|c|c|c|c|c|c|}
\hline Alternative & Abscissa & Unit weight & Cumulative weight & Alternative & Ordinate & Unit weight & Cumulative weight \\
\hline$a$ & $X_{i}$ & $V_{i} \cdot R_{i}$ & $\Sigma$ & $a$ & $Y_{i}$ & $V_{i} \cdot R_{i}$ & $\Sigma$ \\
\hline Karlovac & 43 & 10.80 & 10.80 & Osijek & 20 & 3.00 & 3.00 \\
\hline Koprivnica & 112 & 3.60 & 17.40 & Split & 190 & 10.80 & 22.80 \\
\hline Slavonski Brod & 190 & 9.00 & 26.40 & Slavonski Brod & 199 & 9.00 & 31.80 \\
\hline
\end{tabular}

Table 5 Criteria definition with preference relation

\begin{tabular}{|l|c|c|c|c|c|}
\hline \multicolumn{1}{|c|}{ Criteria } & Goods flow & Infrastructure & Labour market & Port influence & City logistics \\
\hline Goods flow & 1.00 & 3.00 & 5.00 & 4.00 & 0.33 \\
\hline Infrastructure & 0.33 & 1.00 & 2.00 & 0.33 & 3.00 \\
\hline Labour market & 0.20 & 0.50 & 1.00 & 2.00 & 2.00 \\
\hline Port influence & 0.25 & 3.00 & 0.50 & 3.00 & 0.33 \\
\hline City logistics & 3.00 & 0.33 & 0.50 & 3.00 & 1.00 \\
\hline$\sum$ & 4.78 & 7.83 & 9.00 & 2.33 & 6.67 \\
\hline
\end{tabular}




$$
A=\left[\begin{array}{lllll}
1,00 & 3,00 & 5,00 & 4,00 & 0,33 \\
0,33 & 1,00 & 2,00 & 0,33 & 3,00 \\
0,20 & 0,50 & 1,00 & 2,00 & 2,00 \\
0,25 & 3,00 & 0,50 & 1,00 & 0,33 \\
3,00 & 0,33 & 0,50 & 3,00 & 1,00
\end{array}\right]
$$

Requested eigenvector's components are obtained by summing each row values from matrices $A, A \cdot A, A \cdot A$. $A$... till the components reiterate themselves. Calculating $A^{6}$ from (22) we obtain the normalized eigenvector which indicates that the first criteria is the most important one:

$$
w_{0}=\left[\begin{array}{l}
0,31 \\
0,19 \\
0,14 \\
0,13 \\
0,23
\end{array}\right]
$$

Now we have to compare the alternatives considering the criteria given in Table 5. For goods flow there is a matrix

$$
A_{G F}=\left[\begin{array}{lllll}
1,00 & 3,00 & 5,00 & 4,00 & 0,33 \\
0,33 & 1,00 & 2,00 & 0,33 & 3,00 \\
0,20 & 0,50 & 1,00 & 2,00 & 2,00 \\
0,25 & 3,00 & 0,50 & 1,00 & 0,33 \\
3,00 & 0,33 & 0,50 & 3,00 & 1,00
\end{array}\right]
$$

Calculating $A_{G F}$ from (24) we obtain the normalized eigenvector which indicate that the first criteria is the most important one.

$$
w_{G F}=\left[\begin{array}{l}
0,44 \\
0,07 \\
0,18 \\
0,28 \\
0,03
\end{array}\right]
$$

For the infrastructure there is a matrix

$$
A_{I N}=\left[\begin{array}{lllll}
1,00 & 3,00 & 5,00 & 4,00 & 0,33 \\
0,33 & 1,00 & 2,00 & 0,33 & 3,00 \\
0,20 & 0,50 & 1,00 & 2,00 & 2,00 \\
0,25 & 3,00 & 0,50 & 1,00 & 0,33 \\
3,00 & 0,33 & 0,50 & 3,00 & 1,00
\end{array}\right]
$$

Calculating $A_{I N}$ from (26) we obtain the normalized eigenvector which indicate that the fifth criteria is the most important one.

$$
w_{I N}=\left[\begin{array}{l}
0,05 \\
0,10 \\
0,16 \\
0,22 \\
0,47
\end{array}\right]
$$

For the labour market there is a matrix

$$
A_{L M}=\left[\begin{array}{lllll}
1,00 & 3,00 & 5,00 & 4,00 & 0,33 \\
0,33 & 1,00 & 2,00 & 0,33 & 3,00 \\
0,20 & 0,50 & 1,00 & 2,00 & 2,00 \\
0,25 & 3,00 & 0,50 & 1,00 & 0,33 \\
3,00 & 0,33 & 0,50 & 3,00 & 1,00
\end{array}\right]
$$

Calculating $A_{L M}$ from (28) we obtain the normalized eigenvector which indicate that the fifth criteria is the most important one.

$$
w_{L M}=\left[\begin{array}{l}
0,13 \\
0,07 \\
0,05 \\
0,27 \\
0,48
\end{array}\right]
$$

For the port impact there is a matrix

$$
A_{P I}=\left[\begin{array}{lllll}
1,00 & 3,00 & 5,00 & 4,00 & 0,33 \\
0,33 & 1,00 & 2,00 & 0,33 & 3,00 \\
0,20 & 0,50 & 1,00 & 2,00 & 2,00 \\
0,25 & 3,00 & 0,50 & 1,00 & 0,33 \\
3,00 & 0,33 & 0,50 & 3,00 & 1,00
\end{array}\right]
$$

Calculating $A_{P I}$ from (30) we obtain the normalized eigenvector which indicate that the third criteria is the most important one.

$$
w_{P I}=\left[\begin{array}{l}
0,25 \\
0,10 \\
0,42 \\
0,19 \\
0,04
\end{array}\right]
$$

For the city logistics there is a matrix

$$
A_{C L}=\left[\begin{array}{lllll}
1,00 & 3,00 & 5,00 & 4,00 & 0,33 \\
0,33 & 1,00 & 2,00 & 0,33 & 3,00 \\
0,20 & 0,50 & 1,00 & 2,00 & 2,00 \\
0,25 & 3,00 & 0,50 & 1,00 & 0,33 \\
3,00 & 0,33 & 0,50 & 3,00 & 1,00
\end{array}\right]
$$

Calculating $A_{C L}$ from (32) we obtain the normalized eigenvector which indicate that the fifth criteria is the most important one.

$$
w_{C L}=\left[\begin{array}{l}
0,13 \\
0,06 \\
0,04 \\
0,24 \\
0,53
\end{array}\right]
$$

Final result is obtained by multiplying the matrix, consisted of alternative eigenvectors as columns, with criteria eigenvector $w_{0}:\left[w_{G F}: w_{I N}: w_{L M}: w_{P I}: w_{C L}\right]$. In practice, the result is:

$$
C_{A}=\left[\begin{array}{lllll}
0,44 & 0,05 & 0,13 & 0,25 & 0,13 \\
0,07 & 0,10 & 0,07 & 0,10 & 0,06 \\
0,18 & 0,16 & 0,05 & 0,42 & 0,04 \\
0,28 & 0,22 & 0,27 & 0,19 & 0,24 \\
0,03 & 0,47 & 0,48 & 0,04 & 0,53
\end{array}\right] \cdot\left[\begin{array}{l}
0,31 \\
0,19 \\
0,14 \\
0,13 \\
0,23
\end{array}\right]=
$$$$
=\left[\begin{array}{l}
0,15 \\
0,06 \\
0,12 \\
0,20 \\
0,29
\end{array}\right]
$$

Table 6 shows final results obtained by AHP method where alternatives are ranked by preferences. 
Table 6 Ranking alternatives according to preferences

\begin{tabular}{|c|c|c|}
\hline No. & Alternative & Preference \\
\hline 1 & Split & 0.29 \\
\hline 2 & Osijek & 0.20 \\
\hline 3 & Slavonski Brod & 0.15 \\
\hline 4 & Koprivnica & 0.12 \\
\hline 5 & Karlovac & 0.06 \\
\hline
\end{tabular}

Table 7 Alternative comparison according to criteria

\begin{tabular}{|l|c|c|c|c|c|}
\hline \multicolumn{1}{|c|}{ Alternatives } & Goods flow & Infrastructure & Labour market & Port influence & City logistics \\
\hline Slavonski Brod & 8 & 7 & 6 & 7 & 7 \\
\hline Karlovac & 6 & 5 & 6 & 7 & 8 \\
\hline Koprivnica & 7 & 6 & 5 & 6 & 8 \\
\hline Osijek & 5 & 6 & 7 & 4 & 9 \\
\hline Split & 7 & 7 & 8 & 4 \\
\hline
\end{tabular}

Table 8 Weights coefficients for each criteria

\begin{tabular}{|l|c|c|c|c|c|}
\hline Criteria & Goods flow & Infrastructure & Labour market & Port influence & City logistics \\
\hline Weights & 9 & 7 & 5 & 6 & 8 \\
\hline
\end{tabular}

Input values necessary for constructing the matrix $H$ from (13) and vector $B$ from (14) in ELECTRE method are given by Table 7 and Table 8 respectively.

Steps mentioned in chapter 1 are now processed.

In the first step the matrix

$$
R=\left[\begin{array}{lllll}
0,5357 & 0,5013 & 0,4140 & 0,4937 & 0,4276 \\
0,5013 & 0,3581 & 0,4140 & 0,4232 & 0,4276 \\
0,4140 & 0,4297 & 0,3450 & 0,5643 & 0,3054 \\
0,4937 & 0,4297 & 0,4830 & 0,4232 & 0,4887 \\
0,4276 & 0,5013 & 0,5521 & 0,2821 & 0,5498
\end{array}\right]
$$

The second step is processed by formula (16) and provide the following matrix:

$$
V=\left[\begin{array}{lllll}
4,8213 & 3,5091 & 2,0700 & 2,9622 & 3,4208 \\
4,5117 & 2,5067 & 2,0700 & 2,5392 & 3,4208 \\
3,7260 & 3,0079 & 1,7241 & 3,3858 & 2,4432 \\
4,4430 & 3,0079 & 2,4150 & 2,5392 & 3,9096 \\
3,8484 & 3,5091 & 2,7605 & 1,6926 & 4,3984
\end{array}\right]
$$

Third step is left for the reader. For example, $C_{43}=\{2,3,5\}$. In step four, concordance matrix $(C)$ and discordance matrix $(D)$ are obtained by formula (17) and (18) respectively.

$$
\begin{aligned}
C & =\left[\begin{array}{ccccc}
- & 35 & 29 & 22 & 22 \\
13 & - & 13 & 15 & 15 \\
6 & 22 & - & 22 & 15 \\
13 & 12 & 12 & - & 6 \\
20 & 29 & 29 & 29 & -
\end{array}\right] \\
D & =\left[\begin{array}{ccccc}
- & 0,0000 & 0,2174 & 1,0000 & 1,0000 \\
1,0000 & - & 1,0000 & 1,0000 & 1,0000 \\
1,0000 & 0,8914 & - & 1,0000 & 1,0000 \\
0,7360 & 0,3009 & 0,5373 & - & 0,6428 \\
1,0000 & 0,9862 & 0,9123 & 0,5065 & -
\end{array}\right]
\end{aligned}
$$

In fifth and six step, according to (19) and (20):

$$
\begin{aligned}
& \underline{c}=\frac{379}{5(5-1)}=18,95 \\
& \underline{d}=\frac{15,7309}{5(5-1)}=0,7865
\end{aligned}
$$

Considering the values $\underline{c}$ and $\underline{d}$ in (39) and (40) we can obtain dominance matrices of concordance $F$ and of discordance $G$ by step seven.

$$
\begin{aligned}
F & =\left[\begin{array}{ccccc}
- & 1 & 1 & 1 & 1 \\
0 & - & 0 & 0 & 0 \\
0 & 1 & - & 1 & 0 \\
0 & 0 & 0 & - & 0 \\
1 & 1 & 1 & 1 & -
\end{array}\right] \\
G & =\left[\begin{array}{ccccc}
- & 0 & 0 & 1 & 1 \\
1 & - & 1 & 1 & 1 \\
1 & 1 & - & 1 & 1 \\
0 & 0 & 0 & - & 0 \\
1 & 1 & 1 & 0 & -
\end{array}\right]
\end{aligned}
$$

Finally, we get matrix $E=F \cdot G$ :

$$
E=\left[\begin{array}{ccccc}
- & 0 & 0 & 1 & 1 \\
0 & - & 0 & 0 & 0 \\
0 & 1 & - & 1 & 0 \\
1 & 0 & 0 & - & 0 \\
1 & 1 & 1 & 0 & -
\end{array}\right]
$$

By the ELECTRE method the best alternative to solve ITL problem is the one with the highest number of value 1 in the row of matrix $E$ (43). 
From Table 9 it is clear that Split is the best alternative.

Given data for using the PROMETHEE method are in the next two tables. As in the all methods above, here the five alternatives and five criteria are observed. Table 10 displays criteria functions and Table 11 displays criteria estimations.

The last alternative (Split) is obviously dominate and there for it is excluded from further observations.
Table 9 Number of values 1 for each alternative

\begin{tabular}{|l|c|}
\hline \multicolumn{1}{|c|}{ Alternative } & Totality of value $\mathbf{1}$ in the row of E \\
\hline Slavonski Brod & 2 \\
\hline Karlovac & 0 \\
\hline Koprivnica & 2 \\
\hline Osijek & 0 \\
\hline Split & 3 \\
\hline
\end{tabular}

Table 10 Criteria functions

\begin{tabular}{|l|c|c|c|c|c|c|}
\hline \multicolumn{1}{|c|}{ Alternatives } & Alternative mark & Goods flow & Infrastructure & Labour market & Port influence & City logistics \\
\hline Slavonski Brod & A & 4 & 3 & 34,212 & 2.18 & 2 \\
\hline Karlovac & B & 4 & 4 & 33,632 & 1.89 & 2 \\
\hline Koprivnica & C & 2 & 2 & 36,011 & 2.42 & 3 \\
\hline Osijek & D & 3 & 3 & 84,765 & 1.39 & 4 \\
\hline Split & E & 5 & 4 & 158,226 & 0.62 & 5 \\
\hline
\end{tabular}

Table 11 Criteria estimations

\begin{tabular}{|l|c|c|c|c|c|}
\hline \multicolumn{1}{|c|}{ Criteria estimation } & Goods flow & Infrastructure & Labour market & Port influence & City logistics \\
\hline Importance factor & 0.5 & 0.3 & 0 & 0.2 & 0.2 \\
\hline Indifference threshold $q$ & 0 & 0 & 580 & 0.24 & 0.5 \\
\hline Preference threshold $p$ & 0 & 0 & 0 & 0 & \\
\hline
\end{tabular}

Each of five preference functions is defined by (21). The following tables display preference functions for each possible pear of alternatives according to every criteria functions.

Table 12 Preference function for Goods flow criterion

\begin{tabular}{|c|c|c|}
\hline Alternative pair & $\boldsymbol{d}$ & $\boldsymbol{P}(\boldsymbol{d})$ \\
\hline$(\mathrm{A}, \mathrm{B})$ & $4-4=0$ & 0 \\
\hline$(\mathrm{A}, \mathrm{C})$ & $4-2=2$ & 1 \\
\hline$(\mathrm{A}, \mathrm{D})$ & $4-3=1$ & 1 \\
\hline$(\mathrm{B}, \mathrm{A})$ & $4-4=0$ & 0 \\
\hline$(\mathrm{B}, \mathrm{C})$ & $4-2=2$ & 1 \\
\hline$(\mathrm{B}, \mathrm{D})$ & $4-3=1$ & 1 \\
\hline$(\mathrm{C}, \mathrm{A})$ & $2-4=-2$ & 0 \\
\hline$(\mathrm{C}, \mathrm{B})$ & $2-4=-2$ & 0 \\
\hline$(\mathrm{C}, \mathrm{D})$ & $2-3=-1$ & 0 \\
\hline$(\mathrm{D}, \mathrm{A})$ & $3-4=-1$ & 0 \\
\hline
\end{tabular}

Table 13 Preference function for Infrastructure criterion

\begin{tabular}{|c|c|c|}
\hline Alternative pair & $\boldsymbol{d}$ & $\boldsymbol{P}(\boldsymbol{d})$ \\
\hline$(\mathrm{A}, \mathrm{B})$ & $3-4=-1$ & 0 \\
\hline$(\mathrm{A}, \mathrm{C})$ & $3-2=1$ & 1 \\
\hline$(\mathrm{A}, \mathrm{D})$ & $3-3=0$ & 0 \\
\hline$(\mathrm{B}, \mathrm{A})$ & $4-3=1$ & 1 \\
\hline$(\mathrm{B}, \mathrm{C})$ & $4-2=2$ & 1 \\
\hline$(\mathrm{B}, \mathrm{D})$ & $4-3=1$ & 1 \\
\hline$(\mathrm{C}, \mathrm{A})$ & $2-3=-1$ & 0 \\
\hline$(\mathrm{C}, \mathrm{B})$ & $2-4=-2$ & 0 \\
\hline$(\mathrm{C}, \mathrm{D})$ & $2-3=-1$ & 0 \\
\hline$(\mathrm{D}, \mathrm{A})$ & $3-3=0$ & 0 \\
\hline$(\mathrm{D}, \mathrm{B})$ & $3-4=-1$ & 0 \\
\hline$(\mathrm{D}, \mathrm{C})$ & $3-2=1$ & 1 \\
\hline
\end{tabular}

According to Table 11, the preference function given by (21) is modified for labor market criterion into formula (44):

$$
P(x)= \begin{cases}0, & x \leq 580 \\ 1, & x>580\end{cases}
$$

Table 14 Preference function for Labour market criterion

\begin{tabular}{|c|r|c|}
\hline Alternative pair & $\boldsymbol{d}$ & $\boldsymbol{P}(\boldsymbol{d})$ \\
\hline$(\mathrm{A}, \mathrm{B})$ & 580 & 0 \\
\hline$(\mathrm{A}, \mathrm{C})$ & $-1,799$ & 0 \\
\hline$(\mathrm{A}, \mathrm{D})$ & $-50,553$ & 0 \\
\hline$(\mathrm{B}, \mathrm{A})$ & -580 & 0 \\
\hline$(\mathrm{B}, \mathrm{C})$ & $-2,379$ & 0 \\
\hline$(\mathrm{B}, \mathrm{D})$ & $-51,133$ & 0 \\
\hline$(\mathrm{C}, \mathrm{A})$ & 1,799 & 1 \\
\hline$(\mathrm{C}, \mathrm{B})$ & 2,379 & 1 \\
\hline$(\mathrm{C}, \mathrm{D})$ & $-48,754$ & 0 \\
\hline$(\mathrm{D}, \mathrm{A})$ & 50,553 & 1 \\
\hline$(\mathrm{D}, \mathrm{B})$ & 51,133 & 1 \\
\hline$(\mathrm{D}, \mathrm{C})$ & 48,754 & 1 \\
\hline & &
\end{tabular}

According to Table 11, the preference function given by (21) is modified for Port impact criterion into formula (45):

$$
P(x)=\left\{\begin{aligned}
0, & x \leq 0,24 \\
\frac{x-0,24}{0,5-0,24}, & 0,24<x \leq 0,5 \\
1, & x>0,5
\end{aligned}\right.
$$


Table 15 Preference function for Port impact criterion

\begin{tabular}{|c|c|c|}
\hline Alternative pair & $\boldsymbol{d}(\boldsymbol{d})$ \\
\hline$(\mathrm{A}, \mathrm{B})$ & 0.29 & 1 \\
\hline$(\mathrm{A}, \mathrm{C})$ & -0.24 & 0 \\
\hline$(\mathrm{A}, \mathrm{D})$ & 0.79 & 1 \\
\hline$(\mathrm{B}, \mathrm{A})$ & -0.29 & 0 \\
\hline$(\mathrm{B}, \mathrm{C})$ & -0.53 & 0 \\
\hline$(\mathrm{B}, \mathrm{D})$ & 0.5 & 1 \\
\hline$(\mathrm{C}, \mathrm{A})$ & 0.24 & 0 \\
\hline$(\mathrm{C}, \mathrm{B})$ & 0.53 & \\
\hline$(\mathrm{C}, \mathrm{D})$ & 1.03 & \\
\hline$(\mathrm{D}, \mathrm{A})$ & -0.79 & \\
\hline (D, B) & -0.5 & 1 \\
\hline (D, C) & -1.03 \\
\hline
\end{tabular}

Preference function for City logistics criterion, according to Table 11 is calculated by (21).

Table 16 Preference function for City logistics criterion

\begin{tabular}{|c|c|c|}
\hline Alternative pair & $d$ & $P(d)$ \\
\hline$(\mathrm{A}, \mathrm{B})$ & $2-2=0$ & 0 \\
\hline$(\mathrm{A}, \mathrm{C})$ & $2-3=-1$ & 0 \\
\hline$(\mathrm{B}, \mathrm{A})$ & $2-2=0$ & 0 \\
\hline$(\mathrm{B}, \mathrm{C})$ & $2-3=-1$ & 0 \\
\hline$(\mathrm{B}, \mathrm{D})$ & $2-4=0$ & 0 \\
\hline$(\mathrm{C}, \mathrm{B})$ & $3-2=1$ & 1 \\
\hline$(\mathrm{C}, \mathrm{D})$ & $3-4=-1$ & 0 \\
\hline$(\mathrm{D}, \mathrm{A})$ & $4-2=2$ & 1 \\
\hline$(\mathrm{D}, \mathrm{B})$ & $4-2=2$ & 1 \\
\hline$(\mathrm{D}, \mathrm{C})$ & $4-3=1$ & 1 \\
\hline
\end{tabular}

Final results table is filed with preference function values as follows.

Table 17 Final results of preference functions

\begin{tabular}{|c|c|c|c|c|c|}
\hline & Goods flow & Infrastructure & Labour market & Port influence & City logistics \\
\hline$(A, B)$ & 0 & 0 & 0 & 1 & 0 \\
\hline$(\mathrm{A}, \mathrm{C})$ & 1 & 1 & 0 & 0 & 0 \\
\hline$(B, A)$ & 0 & 1 & 0 & 0 & 0 \\
\hline$(\mathrm{B}, \mathrm{C})$ & 1 & 1 & 0 & 0 & 0 \\
\hline$(\mathrm{B}, \mathrm{D})$ & 1 & 1 & 0 & 1 & 0 \\
\hline$(\mathrm{C}, \mathrm{B})$ & 0 & 0 & 1 & 1 & 1 \\
\hline$(C, D)$ & 0 & 0 & 0 & 1 & 0 \\
\hline$(\mathrm{D}, \mathrm{A})$ & 0 & 0 & 1 & 0 & 1 \\
\hline$(\mathrm{D}, \mathrm{B})$ & 1 & 0 & 1 & 0 & 1 \\
\hline$(\mathrm{D}, \mathrm{C})$ & 1 & 1 & 1 & 0 & 1 \\
\hline
\end{tabular}


For every alternative pear, according to importance factor from Table 11, preference indices for each pair are calculated as a dot product. Dot products described in chapter 2 give the values displayed in Table 18.

Table 18 Final results

\begin{tabular}{|c|l|c|}
\hline Pair notation & \multicolumn{1}{|c|}{ Alternative pair } & Final result \\
\hline (A, B) & Slavonski Brod, Karlovac & 0.1 \\
\hline (A, C) & Slavonski Brod, Koprivnica & 0.6 \\
\hline (A, D) & Slavonski Brod, Osijek & 0.5 \\
\hline (B, A) & Karlovac, Slavonski Brod & 0.2 \\
\hline (B, C) & Karlovac, Koprivnica & 0.6 \\
\hline (B, D) & Karlovac, Osijek & 0.7 \\
\hline (C, A) & Koprivnica. Slavonski Brod & 0.3 \\
\hline (C, B) & Koprivnica, Karlovac & 0.4 \\
\hline (C, D) & Koprivnica, Osijek & 0.1 \\
\hline (D, A) & Osijek, Slavonski Brod & 0.3 \\
\hline (D, B) & Osijek, Karlovac & 0.7 \\
\hline (D, C) & Osijek, Koprivnica & 0.9 \\
\hline
\end{tabular}

Final result from Table 18. is clearly presented in Table 19 , together with average output flow $\left(T^{+}\right)$and average input flow $\left(T^{-}\right)$.

Table 19 Average output and input flow for each alternative

\begin{tabular}{|l|c|c|c|c|c|}
\hline & Slavonski Brod & Karlovac & Koprivnica & Osijek $^{+}$ & 0.5 \\
\hline Slavonski Brod & - & 0.1 & 0.6 & 0.4 \\
\hline Karlovac & 0.2 & - & 0.6 & 0.7 \\
\hline Koprivnica & 0.3 & 0.4 & - & 0.1 & 0.27 \\
\hline Osijek & 0.3 & 0.7 & 0.9 & 0.63 \\
\hline$T^{-}$ & 0.27 & 0.4 & 0.7 & 0.43 \\
\hline
\end{tabular}

Final alternative ranking is done according to the absolute difference between average input and output flows.

Table 20 Final alternative ranking

\begin{tabular}{|l|c|c|c|c|}
\hline \multicolumn{1}{|c|}{ Alternative } & $\boldsymbol{T}^{+}$ & $\boldsymbol{T}^{-}$ & $|\mathbf{T}|=\boldsymbol{T}^{+}-\boldsymbol{T}^{-}$ & 0.20 \\
\hline Osijek & 0.63 & 0.43 & 0.13 & 1. \\
\hline Slavonski Brod & 0.40 & 0.27 & 0.10 & 2. \\
\hline Karlovac & 0.50 & 0.40 & -0.43 & 3. \\
\hline Koprivnica & 0.27 & 0.70 & 4. \\
\hline
\end{tabular}

Finally, the best alternative for ITL problem is Split. From Table 20, the other alternatives are ranked, so Osijek is second best, then Slavonski Brod is following and at the end are Karlovac and Koprivnica. 


\section{Conclusion}

In this paper we presented a classical gravity method and median method as quantitative methods. Input data for this methods are coordinates of possible ITL which can be taken from a geographic map. The origin of coordinate system is recommended to be a sea port that is connected with inland terminal. Other values needed for classical gravity and median method are taken from current market situation. There might be other important quantity criteria which decision maker can use to obtain appropriate ITL. Complex decision quality methods considered in this paper are Analytic Hierarchical Process (AHP), ELECTRE and PROMETHEE method. Input data is qualitative and depends on decision maker opportunity, experience and sense. Methods are used to objectively analyze several subjective evaluations.

Comparing the final results of observed five mathematical methods, this paper displayed that both quantitative and qualitative methods are giving similar solutions for ITL problem.

\section{References}

[1] Arnold, P, Peeters, D, Thomas, I, Marchand, H.: Pour une localisation optimale des centre de transbordement intermodaux entre re'seaux de transport: formulation et extensions, The Canadian Geographer, 45(3): 427-436, 2001.

[2] Sörensen, K, Vanovermeire, C, Busschaert, S.: Efficient metaheuristics to solve the intermodal terminal location problem, Computers \& Operations Research, 39: 2079-2090, 2012.

[3] Ballis, A., Mavrotas. G.: Freight Village Design Using The Multicriteria Method PROMETHEE, Operational Research, 7(2):213-232, 2007.

[4] Çelik, P., Talha, U.: Assessing The Service Quality of Gsm Operators by ELECTRE I and Promethee Methods, International
Journal of Economic and Administrative Studies, 6(12): 137-160, 2014.

[5] Chan, F.T.S., Kumar, N., Choy, K.L.: Decision-making approach for the distribution centre location problem in a supply chain network using fuzzy- based hierarhical concept, Proceedings of The Institution of Mechanical Engineers Part B- Journal of Engineering Manufacture, 221(4): 725-739, 2007.

[6] Farahani, R.Z., Hekmatfar, M.: Facility locations, Concepts, Models, Algorithms and Case Studies, Springer, 2009.

[7] Kesić, B., Jugović, A.: Potrebe i mogućnosti organizacije logističko-distribucijskog centra u riječkoj regiji, Pomorstvo: Scientific Journal of Maritime Research, 42(1): 187-208, 2003.

[8] Pašagić Škrinjar, J., Rogić, K., Stanković, R.: Location of Urban Logistic Terminals as Hub Location Problem, Promet Traffic\&Transportation, 24(5): 433-440, 2012.

[9] Rožić, T., Petrović, M., Ogrizović, D.: Container Transport Flows as a Prerequisite for Determination of Inland Terminal Location, Pomorstvo: Scientific Journal of Maritime Research, 28(1): 3-9, 2014.

[10] Satty, R.W: The analytic hierarchy process-what it is and how it is used, Mathematical Modelling, 9(3-5): 161-176, 1987.

[11] Schniederjans, M.J.: International Facility Acquisition and Location Analysis, Quorum books, 1999.

[12] Tomić, V., Marinković, D., Marković, D.: The Selection of Logistic Centers Location using Multi-criteria Comparison: Case Study of the Balkan Peninslula, Acta Polytechnica Hungarica, Hungary, 11(10), 2014.

[13] Uysal, H.T., Yavuz, H.: Selection of Logistics Centre Location via ELECTRE Method: A Case Study in Turkey, International Journal of Business and Social Science, 5(9), 2014.

[14] Van Thai, V., Grewal, D.: Selecting the location of distributon centre in logistics operation a conceptual framework and case study, Asia Pacific Journal of Marketing and Logistics, 17(3): 3-24, 2005.

[15] Żak, J, Węgliński, S: The Selection of the Logistics Center Location Based on MCDM/A Methodology, Transportation Research Procedia, 3: 555-564, 2014. 